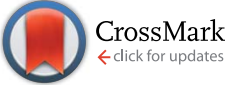

Cite this: RSC Adv., 2016, 6, 44932

\title{
An optimized purification process for porcine gastric mucin with preservation of its native functional properties $\uparrow$
}

\author{
Veronika J. Schömig, ${ }^{a}$ Benjamin T. Käsdorf, ${ }^{b}$ Christoph Scholz, ${ }^{a}$ \\ Konstantinia Bidmon, ${ }^{\mathrm{b}}$ Oliver Lieleg ${ }^{\mathrm{b}}$ and Sonja Berensmeier ${ }^{\star a}$
}

\begin{abstract}
Purified gastric mucins are currently used for a wide range of applications e.g. as a model system for native mucus, as lubricants or antiviral/antibacterial supplements. However, commercially available porcine gastric mucins (PGM) do not exhibit gel-forming properties and show only greatly reduced anti-viral/anti-bacterial activity. Thus, we established a robust purification process for PGM, maintaining its desired properties such as lubricity, gel formation and the selective binding of molecules. We optimized the process in terms of yield and productivity and evaluated the influence of different buffer conditions on mucin quality. Cross-flow filtration using $100 \mathrm{kDa}$ membranes was introduced and optimized to pre-concentrate the mucin solution prior to size exclusion chromatography. A conductivity of less than $100 \mu \mathrm{sm}^{-1}$ after diafiltration was found to be crucial for gel formation. The mucin yield of the optimized process was $66 \%$. The scale-up resulted in a productivity of $0.15 \mathrm{mg}$ purified mucin per $\mathrm{mL}$ crude mucus an hour. In total, approx. $65 \mathrm{mg}$ mucin could be purified from one pig stomach. Tribological studies, rheological measurements and co-localization experiments confirmed the retained functionality of purified mucin in terms of lubricity, gel formation and binding interactions with charged molecules, respectively.
\end{abstract}

Received 21st March 2016

Accepted 23rd April 2016

DOI: $10.1039 / c 6 r a 07424 c$

www.rsc.org/advances nature of mucins at neutral $\mathrm{pH}^{4-6}$ can lead to electrostatic interactions with cationic groups, as they are present on the surface of many bacteria and viruses.

In monomeric form, mucin has a molecular weight of about $640 \mathrm{kDa}^{7}$ where the carbohydrates amount up to $80 \%$ of the whole mass, whereas the protein backbone only contributes $20 \%$ of the weight. ${ }^{8}$ These mainly O-linked glycans such as $\mathrm{N}$-acetylgalactosamine, $\mathrm{N}$-acetylglucosamine, fucose, galactose and sialic acid ( $N$-acetylneuraminic acid) are attached to the hydroxyl side chains of threonine and serine. Mucins are rich in cysteines, which form inter- and intramolecular disulfide bonds resulting in oligomers and polymers of up to $40 \mathrm{MDa}^{8-10}$ Once the disulfide interactions are chemically reduced, mucin gel formation is disturbed. ${ }^{10}$ Additionally, the $\mathrm{pH}$ and ionic strength determine the conformation of native mucin. ${ }^{11}$ The mechanism of the gel formation of mucins like Muc5AC has been investigated in various studies but is not fully understood. ${ }^{5,11-15}$ It seems, in addition to the disulfide bonds, a complex interplay between hydrophobic and electrostatic interactions is responsible for the crosslinking of gel-forming mucins ${ }^{16}$ that is observed at acidic $\mathrm{pH}$.

Native mucin has shown promising properties regarding the adsorption onto ${ }^{4}$ and lubrication of surfaces ${ }^{17-19}$ which could be very interesting for biomedical applications. Moreover, by investigating the bulk and surface properties of mucin layers and gels, a better understanding of native mucus and its 
permeability towards molecules, ${ }^{20,21}$ nanoparticles ${ }^{22}$ and pathogens $^{2}$ can be achieved. Although porcine gastric mucins are commercially available e.g. from Sigma Aldrich, most commercial mucins do not form a hydrogel, are only partially purified and are inferior in inhibiting virus infection compared to natively purified mucins obtained in the lab. ${ }^{2}$ In cell culture experiments $^{2}$ even cell toxic effects were observed when epithelial cells were treated with reconstituted solutions of commercial mucin. Commercial mucins are often further purified with anion exchange chromatography, size exclusion chromatography (SEC) ${ }^{21}$ or centrifugation and filtered through a dead end filter to remove aggregates and undesired proteins. ${ }^{23}$ Nevertheless, in our hands, gel formation of commercially obtained PGMs could not be reconstructed even after further purification (unpublished data). Also Kočevar-Nared and coworkers $^{\mathbf{1 6}}$ found that commercial mucins cannot reproduce the properties of native gastric mucus, which limits the usefulness of commercial mucins e.g. for experiments mimicking the barrier properties of native mucus towards pathogens. The origin of the missing gel formation abilities of commercial mucin is not completely understood, but the purification process itself or fragmentation with proteases are possible explanations. ${ }^{24}$

Several studies have been performed to purify enzymatically digested or chemically reduced mucins using SEC or $\mathrm{CsCl}$ density centrifugation..$^{\mathbf{8 2 5}-27}$ Also, the addition of protease inhibitors and stabilizers is widely used in the purification of mucins ${ }^{\mathbf{1 3 , 2 8 , 2 9}}$ but can complicate the purification process. The purification of native mucin from pig colonic mucosa has been published. ${ }^{26}$ However, so far most purification attempts have been carried out with the aim to further process the glycoproteins or to characterize the purified mucins. To our knowledge, optimizing the yield and productivity of a mucin purification from pig stomachs has not been addressed yet. Such an optimization of the purification process is, however, crucial to meet the growing demand for functional PGM, be it for further academic studies or for biomedical applications.

Therefore, our aim was to establish a robust downstream process to purify native porcine gastric mucin while maintaining its unique properties. We addressed the following aspects that are crucial in downstream processing: (1) the requirement for additives, temperature and buffering conditions during purification, (2) volume reduction for increased product concentration and less process streams, (3) functionality of the protein, (4) improvement of the total yield and (5) higher productivity. First, we established a reproducible protocol in small scale before implementing the changes to an upscaled system. We introduced and optimized cross-flow filtration as a new process unit to achieve a reduction of the initial volume and depletion of small molecules before size exclusion chromatography. To our knowledge, this process unit has so far not been published as a concentration step of mucins, but has high potential in enhancing the protein yield. After further purification by subsequent SEC and diafiltration, functionality tests of PGM solutions and gels were used to verify the success of our optimized process.

\section{Experimental}

\subsection{Materials}

Commercial porcine gastric mucins (PGM) type II and III were obtained from Sigma Aldrich (St. Louis, United States), Schiff's stain and periodic acid 1\% were purchased from Carl Roth (Karlsruhe, Germany), antibodies against Muc5AC (ABIN966608) and horse radish peroxidase HRP conjugated antibodies (ABIN237501) were obtained from antibodiesonline.de (Aachen, Germany). Filter cassettes with a membrane area of $200 \mathrm{~cm}^{2}$ and MWCO of $100 \mathrm{kDa}$ (Hydrosart巴) and $300 \mathrm{kDa}$ MWCO (polyethersulphone, PESU) were obtained from Sartorius Stedim (Goettingen, Germany), Xampler ${ }^{\mathrm{TM}}$ laboratory-scale hollow fiber cartridge with a length of $31.7 \mathrm{~cm}$, an inner diameter of $0.1 \mathrm{~mm}$ and membrane area of $110 \mathrm{~cm}^{2}$ and $100 \mathrm{kDa}$ MWCO (polysulfone) was from GE Healthcare Life Sciences (Freiburg, Germany).

\subsection{Methods}

Sample collection. In general it must be noted, that the mucus samples used for purification are of animal origin and from different stomach batches. Therefore, different yields and variations in the viscoelastic properties of the purified material are likely to occur. However, we pooled the mucus of 20 to 60 stomachs per batch to minimize these variances. We do not focus on variations between different batches, but discuss the properties of our purified mucin in general. Absolute values are to be taken with care and do not indicate significant differences in gel formation abilities of the purified mucins but are the result of natural variances. Sample collection was based on the protocol described by Libao-Mercado and coworkers. ${ }^{8}$ In detail, fresh pig stomachs were obtained from a local slaughterhouse and stored on ice. The stomachs were cut along their longitudinal axis and the remaining food and debris was gently rinsed with tap water. The mucosal surface of the stomach was manually scraped with spoons and the mucus was collected in a beaker placed on ice. A mean volume of $40 \mathrm{~mL}$ mucus was obtained from one stomach. The mucus was diluted 1 to 5 in 10 $\mathrm{mM}$ phosphate buffer $\mathrm{pH} 7.0$ with $170 \mathrm{mM} \mathrm{NaCl}$ containing $0.04 \%(\mathrm{w} / \mathrm{v}) \mathrm{NaN}_{3}$. pH was adjusted to 7.4 and $5 \mathrm{mM}$ benzamidine HCl (Carl Roth, Karlsruhe, Germany), 1 mM 2,4'-dibromoacetophenone (Sigma Aldrich, St. Louis, United States), 1 $\mathrm{mM}$ phenylmethylsulfonyl-fluoride (Carl Roth, Karlsruhe, Germany) and 5 mM EDTA (Carl Roth, Karlsruhe, Germany) pH 7.4 were added and gently stirred over night at $4{ }^{\circ} \mathrm{C}$.

Centrifugation. The solubilized mucus was centrifuged at $8300 \times g$ (Sorvall Evolution RC, SLC-4000 rotor, Thermo Scientific, Waltham, MA, USA) for 30 minutes at $4{ }^{\circ} \mathrm{C}$. Afterwards, the supernatant was again centrifuged at $15000 \times g$ for 45 minutes at $4{ }^{\circ} \mathrm{C}$. The supernatant was stored either at $-20{ }^{\circ} \mathrm{C},-80{ }^{\circ} \mathrm{C}$ or in liquid nitrogen. For further processing, the supernatant was thawed or used directly after the centrifugation steps. An ultracentrifugation step at $150000 \times g$ (Beckman LE-70 Optima, rotor 70-Ti, Beckman Coulter, Krefeld, Germany) for $1 \mathrm{~h}$ at $4{ }^{\circ} \mathrm{C}$ was conducted before filtration. For the upscaled process, the centrifugation steps were identical. 
Concentration. After the processing of porcine mucus, a concentration step (4-5 fold) was conducted at room temperature using cross-flow filtration (SARTOFLOW® Slice 200 benchtop crossflow system, Sartorius AG, Goettingen, Germany, for hollow fiber module: UFP - 100-E-3MA QuixStand GE Healthcare, Freiburg, Germany). The MWCO was 100 or 300 $\mathrm{kDa}$ depending on the experiment with a membrane area of 200 $\mathrm{cm}^{2}$ or $110 \mathrm{~cm}^{2}$ for the hollow fiber membrane. Constant pressure mode was applied with $\Delta p_{\mathrm{TM}}$ between 0.5 and 1.5 bar to achieve the optimized filtration mode with the lowest loss of product. The washing of the membrane was performed in 50 $\mathrm{mL}$ of $10 \mathrm{mM}$ phosphate buffer ( $\mathrm{pH} 7.0$, supplemented with 170 $\mathrm{mM} \mathrm{NaCl}$ ) for $5 \mathrm{~min}$ in circular flow and analyzed for protein content. Samples of retentate, permeate and washing fraction were taken for protein analysis. The washing fraction was added to the retentate. For the upscaled process, a hollow fiber membrane with $100 \mathrm{kDa}$ MWCO and a membrane area of 110 $\mathrm{cm}^{2}$ was used.

Parameter calculation during cross-flow filtration. The filtration performances of various setups were examined using mass transfer relations with the Reynolds (Re) number, the Schmidt (Sc) number and Sherwood (Sh) number. ${ }^{30}$ In laminar flow, the following relation holds:

$$
\mathrm{Sh}=\frac{k d_{\mathrm{h}}}{D}=\frac{d_{\mathrm{h}}}{\delta_{\mathrm{BL}}}=1.62\left(\operatorname{ReSc} \frac{d_{\mathrm{h}}}{L}\right)^{1 / 3}
$$

with $k$ being the mass-transfer coefficient $\left(\mathrm{m} \mathrm{s}^{-1}\right), D$ the diffusion coefficient of the protein $\left(\mathrm{m}^{2} \mathrm{~s}^{-1}\right), d_{\mathrm{h}}$ the hydrodynamic diameter $(\mathrm{m})$, and $\delta_{\mathrm{BL}}$ the thickness of the boundary layer $(\mathrm{m})$. In turbulent flow, Sh is approximated with:

$$
\mathrm{Sh}=0.04 \mathrm{Re}^{3 / 4} \mathrm{Sc}^{1 / 3}
$$

Detailed information is provided in the ESI (Table S1 $\dagger$ ). Also, the permeate flux and fouling resistances during concentration were calculated as follows. Darcy's law (eqn (3)) describes the flow rate of a fluid phase through a porous medium: ${ }^{31}$

$$
J=\frac{\dot{V}}{A}=\frac{\Delta p_{\mathrm{TM}}}{\eta_{\text {perm }} R_{\mathrm{tot}}}
$$

with $J$ being the flux $\left(\mathrm{kg} \mathrm{m} \mathrm{m}^{-2} \mathrm{~h}^{-1}\right) ; \eta_{\text {perm }}$ the viscosity of the permeate (Pa s); $R_{\text {tot }}$ the total resistance of the membrane $\left(\mathrm{m}^{-1}\right)$; $\Delta p_{\mathrm{TM}}$ the transmembrane pressure (bar).

The fouling resistance $R_{\text {fouling }}$ is determined by combining eqn (3) and (4), with $R_{\mathrm{m}}$ being the membrane resistance of water: ${ }^{32}$

$$
R_{\mathrm{tot}}=R_{\mathrm{m}}+R_{\mathrm{fouling}}
$$

Size exclusion chromatography. Size exclusion chromatography to receive fractions according to the molecular weight was conducted using Äkta Explorer (GE Healthcare, Amersham Biosciences, Freiburg, Germany). Sepharose 6 Fast Flow was used as column material (GE Healthcare, UK) with a bed volume of $176 \mathrm{~mL}$ and $1650 \mathrm{~mL}$, respectively. $10 \mathrm{mM}$ phosphate buffer (pH 7.0, supplemented with $170 \mathrm{mM}$ sodium chloride) was used as equilibration buffer and running buffer to elute the target protein. Approx. 0.11 column volumes (CV) $(20 \mathrm{~mL}$ and $180 \mathrm{~mL}$, of the concentrated mucus) were loaded onto the column. The flow rate was $30 \mathrm{~cm} \mathrm{~h}^{-1}$. Absorbance at $280 \mathrm{~nm}$ and $215 \mathrm{~nm}$ were recorded online. Fractions of either 5 or $11 \mathrm{~mL}$ were collected (depending on the column size) and analyzed with ELISA and periodic acid/Schiff's stain (PAS) assay. Glycoprotein containing fractions were pooled and a sample was taken for further analysis.

Diafiltration. In the optimized filtration protocol, pooled fractions were diafiltrated against $\mathrm{ddH}_{2} \mathrm{O}$ with a $100 \mathrm{kDa}$ membrane of $200 \mathrm{~cm}^{2} / 110 \mathrm{~cm}^{2}$ for the hollow fiber membrane and 1 bar transmembrane pressure until a conductivity of $<100$ $\mu \mathrm{S} \mathrm{cm}{ }^{-1}$ was obtained. Washing was performed as described for the concentration step. The protein solution was aliquoted, a sample taken and lyophilized over night at $-60{ }^{\circ} \mathrm{C}$ and 0.06 mbar (Alpha 1-2 LD, Christ, Osterode am Harz, Germany). For the upscaled process, a hollow fiber membrane with $100 \mathrm{kDa}$ MWCO and a membrane area of $110 \mathrm{~cm}^{2}$ was used. Where applicable, the retentate was further concentrated until the dead volume of the module was reached.

\subsection{Analytical methods}

Quantitative PAS-assay. Quantitative periodic acid/Schiff's stain (PAS) assay was used for the detection of carbohydrates. Based on Kilcoyne and coworkers, ${ }^{33}$ the analysis was conducted in microtiter plates (Nunc ${ }^{\circledR}$ MicroWell ${ }^{\mathrm{TM}} \mathrm{F}$ bottom Sigma Aldrich, Crailsheim, Germany) for high throughput determination. In brief, $25 \mu \mathrm{L}$ of sample was pipetted into a well and incubated with $120 \mu \mathrm{L}$ of $0.06 \%(\mathrm{v} / \mathrm{v})$ periodic acid diluted in $7 \%$ $(\mathrm{v} / \mathrm{v})$ acetic acid for $90 \mathrm{~min}$ at room temperature. $100 \mu \mathrm{L}$ Schiff's stain (Carl Roth GmbH \& Co. KG, Karlsruhe, Germany) was added and incubated for another $60 \mathrm{~min}$ at room temperature to allow complete staining of carbohydrates. Absorption was measured at $550 \mathrm{~nm}$ after $5 \mathrm{~s}$ of shaking (Infinite M 200 PRO Series, Software: Magellan V 7.0, Tecan Deutschland $\mathrm{GmbH}$, Crailsheim, Germany). Self-purified mucin was used as standard in the range of $0.125 \mathrm{mg} \mathrm{mL}^{-1}$ to $1 \mathrm{mg} \mathrm{mL}^{-1}$.

ELISA. An indirect ELISA was performed to investigate the gel forming Muc5AC containing samples. $100 \mathrm{~mL}$ samples were pipetted into microtiter plates (Nunc ${ }^{\circledR}$ MicroWell ${ }^{\mathrm{TM}} \mathrm{F}$ bottom Sigma Aldrich, Crailsheim, Germany), incubated with a monoclonal anti-Muc5AC antibody (antibodies-online.de, ABIN966608) and visualized by a secondary antibody labelled with HRP (antibodies-online.de, ABIN237501). Between all incubations, the wells were extensively washed with blocking buffer $(5 \%$ (w/v) milk powder in PBS with $0.1 \%(\mathrm{w} / \mathrm{v})$ Tween 80$)$. The substrate $o$-phenylenediamine (oPD) (Applichem GmbH, Darmstadt, Germany) was added and the enzymatic reaction was stopped with $1 \mathrm{M} \mathrm{H}_{2} \mathrm{SO}_{4}$ after 6-8 min of incubation. Absorption was measured at $490 \mathrm{~nm}$ in a photometer (Infinite $\mathrm{M}$ 200 PRO Series, Software: Magellan V 7.0, Tecan Deutschland $\mathrm{GmbH}$, Crailsheim, Germany). Purified Muc5AC was used as standard in the range of $1.25 \mu \mathrm{g} \mathrm{mL}^{-1}$ to $80 \mu \mathrm{g} \mathrm{mL} \mathrm{m}^{-1} .50 \mathrm{mM}$ carbonate buffer ( $\mathrm{pH}$ 9.6) was used as blank and for the dilution of samples and standard, respectively. 


\subsection{Characterization}

Rheology. Rheological measurements were conducted with either $2 \%(\mathrm{w} / \mathrm{v})$ or $1 \%(\mathrm{w} / \mathrm{v})$ purified mucin. The change in viscoelasticity and the gelation behavior of reconstituted mucin solutions were analyzed as a function of $\mathrm{pH}$. Lyophilized mucin was weighed and hydrated in $90 \% \mathrm{ddH}_{2} \mathrm{O}$ and filled with $10 \%$ of $10 \times$ phosphate buffer $(\mathrm{pH} 2$ or $\mathrm{pH} \mathrm{6)} 2 \mathrm{~h}$ prior to analysis. Rheological evaluation of mucin solutions and gels was performed on a stress-controlled shear rheometer (MCR 302, Anton Paar, Graz, Austria) using a plate/plate measuring setup (PP25, Anton Paar, Graz, Austria) and $125 \mu \mathrm{m}$ plate separation. When determining frequency dependent viscoelastic moduli, small torques in the range of $0.5 \mu \mathrm{Nm}$ were applied to ensure linear material response. $100 \mu \mathrm{L}$ of samples were used for the analysis for full loading of the gap between plate and measuring head. The storage modulus $G^{\prime}$ and loss modulus $G^{\prime \prime}$ were recorded within frequencies of $0.1-10 \mathrm{~Hz}$. The temperature during measurements was set to $21^{\circ} \mathrm{C}$.

Tribology. The friction measurements were conducted with a rotational tribology setup assembled on a shear rheometer (MCR 302, Anton Paar). The rheometer was equipped with a tribology unit (T-PTD 200, Anton Paar), and the measurements were performed in a sphere-on-cylinder geometry as described in Boettcher et. al., 2014. ${ }^{34}$ Steel spheres with a diameter of $12.7 \mathrm{~mm}$ were purchased at Kugel Pompel (Vienna, Austria). The cylinders were prepared by mixing PDMS (SYLGARD 184, Dow Corning) in a $10: 1$ ratio with the curing agent. Air bubbles were removed under vacuum and the PDMS was cured at $80^{\circ} \mathrm{C}$ for $1 \mathrm{~h}$. For each measurement, fresh cylinders were used that were cleaned with $80 \%(\mathrm{v} / \mathrm{v}) \mathrm{EtOH}$ before usage. $600 \mu \mathrm{L}$ of a $0.1 \%(\mathrm{w} / \mathrm{v})$ mucin solution dissolved in $20 \mathrm{mM}$ HEPES ( $\mathrm{pH} 7.4$ ) were added and the steel sphere was rotated on the PDMS cylinders at a normal force of $6 \mathrm{~N}$. The friction behavior was evaluated by performing a speed ramp from 1000 to $0.01 \mathrm{~mm} \mathrm{~s}^{-1}$. The measurements were conducted at $21{ }^{\circ} \mathrm{C}$, and three individual measurements with fresh PDMS cylinders were performed for each condition.

Co-localization experiments. For determining the chargeselective permeability of mucin gels, mucin was rehydrated in $\mathrm{ddH}_{2} \mathrm{O}$ and incubated with $10 \mu \mathrm{g} \mathrm{mL}^{-1}$ lectin (fluorescently labeled with rhodamine, Sigma-Aldrich, St. Louis, USA) for 1 h during shaking at $4{ }^{\circ} \mathrm{C}$. $0.1 \mathrm{mg} \mathrm{mL}^{-1}$ of either negatively charged $150 \mathrm{kDa}$ carboxymethyl (CM) dextrans or positively charged diethylaminoethyl (DEAE) dextrans (both obtained from Sigma-Aldrich, St. Louis, USA) fluorescently labeled with fluorescein isothiocyanate (FITC) were added to the mucin-lectin solution and incubated for another hour during shaking at $4{ }^{\circ} \mathrm{C}$. To induce gelation of the mucin solution, $10 \% 10 \times$ phosphate buffer $(\mathrm{pH} 2)$ was added and the solution incubated for $1 \mathrm{~h}$ during shaking at $4{ }^{\circ} \mathrm{C}$. The final mucin concentration was $1 \%(\mathrm{w} / \mathrm{v})$. Fluorescence microscopy images were obtained on an Axioskop 2 MAT mot microscope (Zeiss, Oberkochen, Germany) equipped with a $20 \times$ objective (Zeiss) using a digital camera (Orca-R2 C10600, Hamamatsu, Japan) and the image acquisition software HCImageLive (Hamamatsu).

\section{Results \& discussion}

A schematic overview of the optimized process is shown in Fig. 1. Dashed lines qualitatively indicate the mucin concentration and dilution during downstream steps. After harvesting the mucus from pig stomachs by manual scraping, the mucus was homogenized in buffer in the ratio $1: 5$, and cells, cell debris and finally lipids were removed in centrifugation steps. After the centrifugation steps, the pellets accounting for 33\% and $10 \%$ of the total volume, were discarded, and we assumed that no mucin was lost within these steps. Next, a concentration step using cross-flow ultrafiltration was introduced. To our knowledge, this novel process step has not yet been published regarding mucin purification. It not only led to depletion of smaller proteins but also entailed an important volume reduction and concentration of the target protein. An increase in productivity was expected because a highly concentrated protein solution was further processed and thereby more protein was loaded onto the SEC while keeping the volume constant. Process parameters such as membrane pore size and

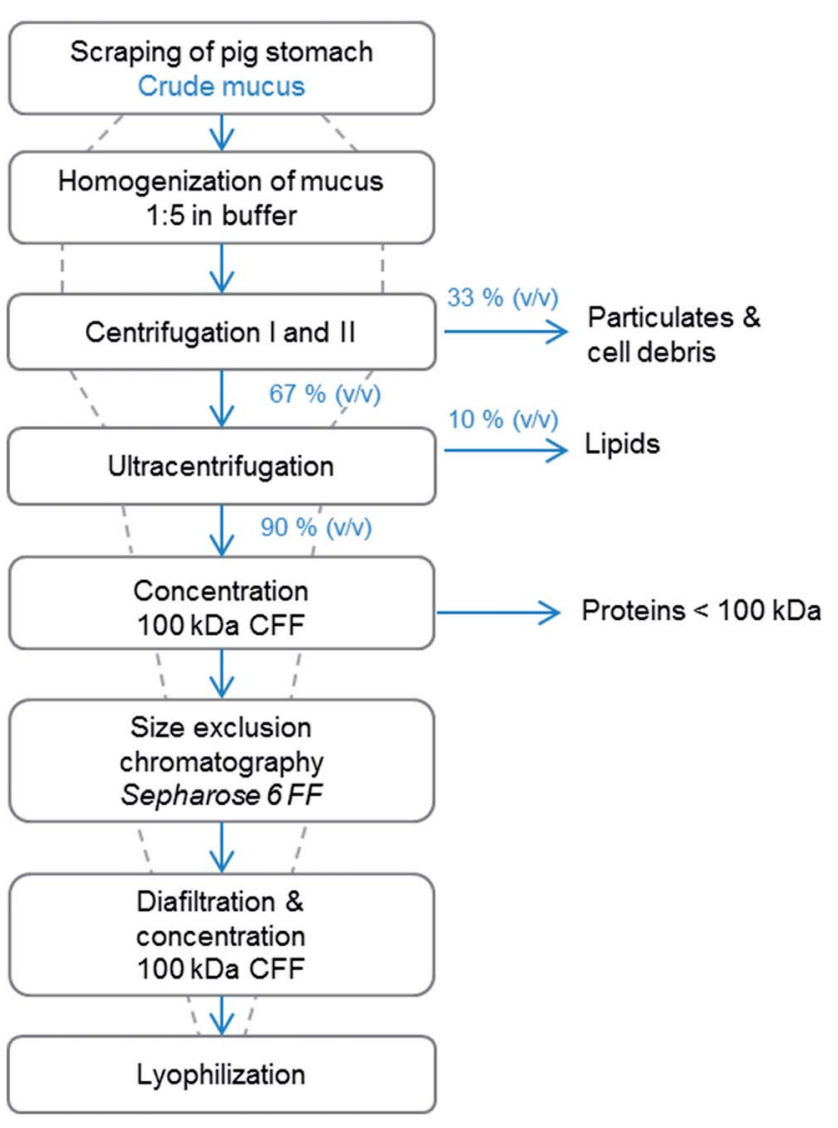

Fig. 1 Schematic illustration of the purification process of mucin from porcine stomachs. The dashed lines indicate the volume reduction or increase after each process step. After centrifugation II, the pellet, accounting for $33 \%$ of the volume, was discarded. After ultracentrifugation, the pellet, consisting of $10 \%$ of the total volume, was removed, before the supernatant was further concentrated with cross-flow filtration (CFF). Size exclusion chromatography was performed and finally salts were removed by CFF before the protein solution was lyophilized. 
membrane system were investigated during cross-flow filtration and the yields of mucin compared. The following step, size exclusion chromatography, has already been used for the purification of mucins from animal or human sources. ${ }^{26,27,35}$ Because of the high molecular weight of mucin in its native form, SEC is suitable for the separation of glycoproteins, and the fractions can be analyzed to detect carbohydrates and mucins. Thereafter, removal of salts (and further concentration in the upscaled process) was conducted by the same cross-flow ultrafiltration system, and the target protein was lyophilized. Samples were taken after each step of the purification process and analyzed both for glycoprotein content in general and Muc5AC content in particular. We did not determine the exact purity of the purified mucin with conventional protein assays such as UV absorption, BCA or Bradford reagent since - due to the high glycosylation density of mucin - the mucin concentration would be underestimated and thereby falsified results would be obtained when referring to a standard curve of a model protein such as BSA.

\subsection{Influence of buffer composition and storage temperature}

As a first step for optimizing the purification process and improving the yield of functional mucin, the influence of buffer additives such as salts and protease inhibitors as well as the influence of different storage temperatures on mucin quality were evaluated.

Influence of buffer. In former studies native mucins were mostly purified using $200 \mathrm{mM} \mathrm{NaCl}$ either as a hydration solution or running solvent during gel filtration. ${ }^{6,8,26,36}$ However, the use of a buffered system for protein solubilization and gel filtration has only been described few times ${ }^{25,36,37}$ where either a Tris-HCl buffer, or a sodium phosphate buffer was used for chromatography. For a robust downstream process buffered systems are especially important for biological systems to retain a reproducible process performance. Due to its $\mathrm{pH}$-induced gelation behavior, the viscosity of mucin solutions is highly sensitive to $\mathrm{pH}$, thus (partial) $\mathrm{pH}$-induced mucin gelation during the purification process may lead to difficulties during chromatography by blocking the column material. We therefore chose a $10 \mathrm{mM}$ sodium phosphate buffer at $\mathrm{pH} 7.0$ for mucin dilution and chromatography to avoid mucin gelation. We added $170 \mathrm{mM} \mathrm{NaCl}$ to this buffer to mimic the total ionic strength used in former purifications. The functionality of mucin purified with this $10 \mathrm{mM}$ sodium phosphate buffer $(\mathrm{pH}$ 7.0 supplemented with $170 \mathrm{mM} \mathrm{NaCl}$ ) was determined with rheological measurements. No differences in the $\mathrm{pH}$-induced gelation behavior of the mucin solutions were observed compared to mucin purified in $200 \mathrm{mM} \mathrm{NaCl}$ (ESI Fig. S2a $\dagger$ ). Additionally, blocking of the column did not occur and stripping of the column could be set to a minimum. Hence, all further purification steps were conducted in a buffered system at $\mathrm{pH}$ 7.0.

Protease inhibitors. Next, process optimization was conducted by testing the necessity of additives like protease inhibitors and stabilizing agents. In small biochemical preparations of proteins from animal tissue, protease inhibitors such as benzamidine $\mathrm{HCl}$ and phenylmethylsulfonylfluoride are traditionally added at the beginning of the purification to protect the proteins from enzymatic cleavage by trypsin or serine proteases. ${ }^{\mathbf{8 1 0}}$ However, the use of additives should - if possible - be avoided: on the one hand, such protease inhibitors are typically toxic and, on the other hand, they constitute further contaminants that need to be removed again in later steps of the purification process. Glycoproteins are in general known for their resistance against proteolytic activity. ${ }^{\mathbf{3 8 - 4 0}}$ Also mucins are relatively insensitive to proteolytic digestion, which is due to their high density of carbohydrate side chains. ${ }^{\mathbf{1 2}}$ However, the highly glycosylated regions of mucin are intersected by non-glycosylated sequences that are protease-sensitive. ${ }^{10}$ In our experiments we could not observe enzymatic proteolysis of PGM at pH 7. This might be explained by the fact that pepsin, the most abundant protease in the stomach, is inactive at neutral $\mathrm{pH} .{ }^{\mathbf{4 1}}$ Thus, we tested a purification protocol at pH 7 and compared mucin functionality after purification in either the presence or the absence of a mix of sodium azide, benzamidine $\mathrm{HCl}$, phenylmethylsulfonylfluoride, 2,4'-dibromoacetophenone, DMSO and EDTA, respectively. Again, we tested the gel-forming ability of the purified mucin and found that the absence of the above named components did not have any influence on mucin gel formation (ESI Fig. S2b $\dagger$ ). This finding allowed us to omit those additives.

Storage temperature. The influence of the freezing and storage temperature of crude mucus (after centrifugation steps I and II) and purified mucin was evaluated by testing the gelation behavior of the corresponding solutions of reconstituted mucins. As freezing conditions for crude mucus and partially purified mucin, we compared snap freezing in liquid nitrogen, freezing in a $-80{ }^{\circ} \mathrm{C}$ freezer and freezing in a $-20{ }^{\circ} \mathrm{C}$ freezer. Our findings indicated that freezing of mucus samples at -80 ${ }^{\circ} \mathrm{C}$ was sufficient and no shock-freezing in liquid nitrogen was necessary. Furthermore, we found that, once lyophilized, the purified mucin is still able to form gels in the range of several pascal, even after long-term storage at room temperature (ESI Fig. S4†).

\subsection{Process optimization of mucin purification}

In general, the purification of proteins includes several steps until the desired purity is reached. In addition to obtaining a pure product, maintaining functionality of the molecule is a key goal. With every step, target protein is lost. Thus, the purification is usually a cost-intensive process making a high recovery of proteins and productivity essential. Early volume reduction is one step to increase the efficiency of the process. Thus, we first introduced cross-flow filtration as an essential measure during the purification process of mucins to achieve a concentration of mucin and, at the same time, depletion of undesired smaller proteins. Using the cross-flow configuration, the protein solution circulates tangentially to the membrane. By applying pressure, the solution permeates through the pores. With this process, less cake formation is observed on the membrane compared to dead-end filtration. ${ }^{42}$ In the following, 
the optimization of this cross-flow filtration is discussed in detail and subsequent size exclusion chromatography is presented.

Cross-flow filtration. For the concentration of centrifuged, partially purified mucin we examined two different systems, i.e. membrane cassettes and a hollow fiber membrane. Also, we varied membrane pore sizes and evaluated the permeate flux and fouling resistances as well as the recovery of the target protein. $\Delta p_{\mathrm{TM}}$ was varied between 0.5 and $1.5 \mathrm{bar}$, and we found that a $\Delta p_{\mathrm{TM}}$ of 1 bar resulted in the highest recovery of mucin in the retentate (ESI Fig. S5 $\dagger$ ). Thus, all following results were obtained using a $\Delta p_{\text {TM }}$ of 1 bar. Two membrane cassettes (100 $\mathrm{kDa}$ Hydrosart®, $300 \mathrm{kDa}$ PESU) and one hollow fiber membrane (100 kDa polysulfone) were compared with respect to flux and fouling resistance calculated according to eqn (3) and (4) (see Experimental). The volume concentration factor (VCF) was kept constant at 4.9 for all filtrations.

As presented in Fig. 2, the flux through the hollow fiber system decreased only weakly with time and reached a nearly constant value of $60 \mathrm{~kg} \mathrm{~m}^{-2} \mathrm{~h}^{-1}$ after $9 \mathrm{~min}$. In contrast the flux through the membrane cassettes decreased much more strongly and reached final values of only $40 \mathrm{~kg} \mathrm{~m}^{-2} \mathrm{~h}^{-1}(300 \mathrm{kDa}$ membrane) and $35 \mathrm{~kg} \mathrm{~m}^{-2} \mathrm{~h}^{-1}$ (100 kDa membrane) respectively, after the same time. For both membrane systems, the fouling resistance reached $4 \times 10^{12} \mathrm{~m}^{-1}$ after $9 \mathrm{~min}$, and there seemed to be a tendency towards even higher values. Conversely, the hollow fiber system reached a nearly constant fouling resistance just below $4 \times 10^{12} \mathrm{~m}^{-1}$.

The three membrane systems were also characterized in terms of their capability to retain glycoproteins in general and our target protein Muc5AC in particular. Fig. 3 displays the recovery of glycoproteins and Muc5AC in the retentate and permeate, respectively, after 4.9 fold volume concentration. The amount of protein collected in the washing steps of the membrane was included in the retentate.

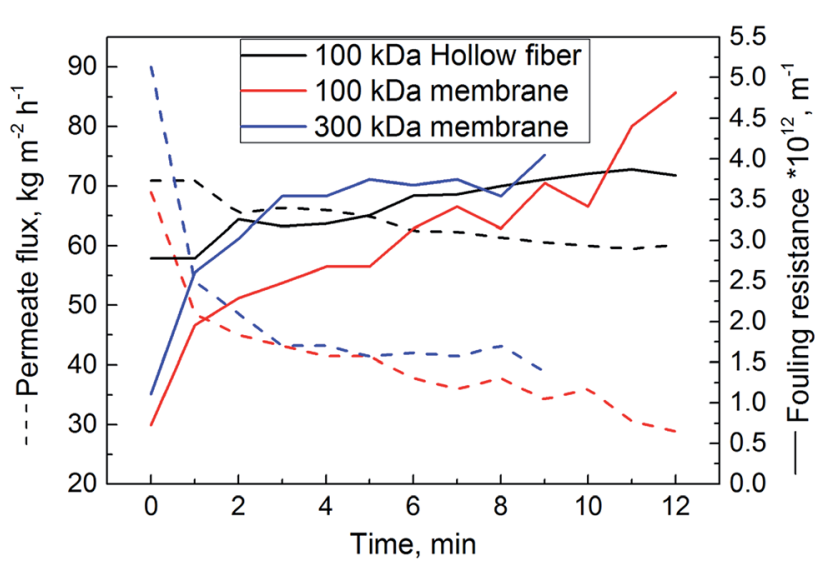

Fig. 2 Permeate flux (dashed lines) and fouling resistance (solid lines) determined for a $100 \mathrm{kDa}$ hollow fiber system and membrane cassettes (100 kDa and $300 \mathrm{kDa}$, respectively) at $\Delta p_{\mathrm{TM}}=1 \mathrm{bar}$. In each setup, $200 \mathrm{~mL}$ of mucin solution (containing $0.27 \mathrm{mg} \mathrm{mL}^{-1}$ Muc5AC) as obtained after the centrifugation steps were used for concentration. In all three systems, mucin concentration was performed until a volume concentration factor of 4.9 was reached.

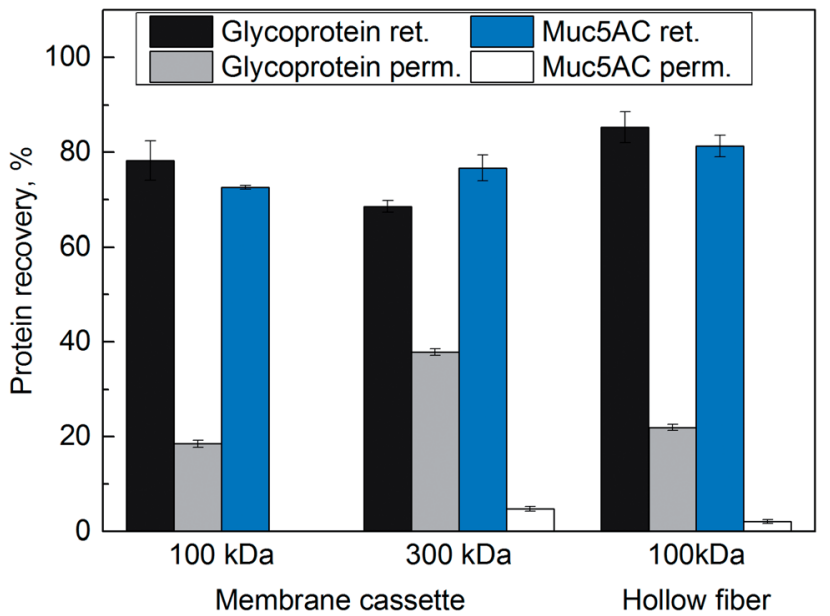

Fig. 3 Recovery of Muc5AC and total glycoprotein measured in the retentate (ret.) and permeate (perm.) after 4.9 fold volume concentration with $100 \mathrm{kDa}$ (Hydrosart $\left.{ }^{\circledR}\right)$ and $300 \mathrm{kDa}$ (PESU) membrane cassettes and $100 \mathrm{kDa}$ hollow fiber membrane (PSU) at $\Delta p_{\mathrm{TM}}=1$ bar. Protein recovered from the washing steps was included in the retentate values. Glycoprotein concentration was determined with quantitative PAS assay, Muc5AC concentration was determined with ELISA. Error bars represent the \pm s.d. of analytical triplicates.

For the $100 \mathrm{kDa}$ membrane cassette, $78 \%$ of the glycoproteins were retrieved in the retentate, whereas $19 \%$ glycoproteins were found in the permeate. The Muc5AC content in the retentate was $73 \%$, the permeate was free of Muc5AC. Similar results were obtained with the hollow fiber module: with this cross-flow system, the recovery of glycoproteins in the retentate and permeate was $85 \%$ and $22 \%$ respectively. $81 \%$ of Muc5AC were retrieved in the retentate, and only $2 \%$ in the permeate. For the $300 \mathrm{kDa}$ membrane, the glycoprotein content in the permeate was twice as high as for the $100 \mathrm{kDa}$ membrane cassette, and $5 \%$ of Muc5AC was found in the permeate.

Glycoproteins as well as glycosylated peptides smaller than the nominal MWCO can pass the membranes. Typically, it is suggested to use a pore size three to six times smaller than the molecular weight of the target protein for successful retention. As Muc5AC has a monomer size of approximately $640 \mathrm{kDa},{ }^{7}$ the MWCO of $300 \mathrm{kDa}$ may not be ideal. Indeed, the highest mucin concentration was detected in the permeate of this cross-flow variant. Both $100 \mathrm{kDa}$ membranes showed a better retention of the target protein Muc5AC in contrast to the $300 \mathrm{kDa}$ membrane as is shown in Fig. 3.

Despite the MWCO, the differences in filtration- and retention behavior might also be explained by the different geometries of the filtration setups. For the ultrafiltration systems used here, diffusion dominates over hydrodynamic effects. ${ }^{30}$ Filtration through a membrane creates a concentration polarization of the protein solution towards the surface which can, in laminar flow conditions, lead to irreversible gel layer formation. To decide which flow conditions apply in our three setups, we estimated the flow within the different modules by calculating the Reynolds number (ESI Table S1 $\dagger$ ). For these calculations, we approximated the mucin solution with the viscosity and density of water $\left(0.89 \mathrm{mPa} \mathrm{s}\right.$ and $1000 \mathrm{~kg} \mathrm{~m} \mathrm{~m}^{-3}$, respectively) and 
assumed a mean diffusion coefficient for mucins of $4 \times 10^{-8}$ $\mathrm{cm}^{2} \mathrm{~s}^{-1} \cdot{ }^{43}$ For all configurations, the boundary layer was calculated using the Sherwood and Schmidt number (see Experimental). The calculated boundary layer thickness was $0.01 \mu \mathrm{m}$ for the hollow fiber system and 19 to $20 \mu \mathrm{m}$ for the membrane cassettes (Table S1 $\uparrow$ ). For the hollow fiber, the calculated Reynolds number suggested a turbulent flow through the filtration area $\left(\mathrm{Re}>4 \times 10^{4}\right)$. Shear forces created by the turbulent flow drag the molecules away from the concentration polarization zone and membrane surface, creating a thinner and mostly reversible boundary layer. A steady state of flux and fouling resistance is reached after a certain time. In contrast, the flow through both membrane cassettes was laminar (Re $<10^{4}$ ). Because laminar flow promotes the deposition of molecules on the membrane surface and thereby leads to a continuous decrease in flux and increase in fouling resistance, as was indeed observed for both membrane cassettes (Fig. 2), we concluded that an irreversible gel layer must have formed on the membranes. The layers built on the membrane cassettes might also explain a loss of product of up to $28 \%$. For the hollow fiber the loss of protein was lower at $17 \%$.

In addition, a difference in the adsorption behavior of mucin on the different membrane materials may have to be considered when it comes to protein loss. Mucins adsorb especially well on hydrophobic surfaces. ${ }^{\mathbf{4} 44,45}$ However, regenerated cellulose as well as polyethersulfone are both hydrophilic materials and are supposed to exhibit only minimal protein binding (as claimed by the manufacturer Sartorius). Together with our observations above and the fact that the hollow fiber system reached a flux twice as high as the membrane cassettes although having a surface area of nearly half the membrane area of the membrane cassettes, we concluded that a hollow fiber system is advantageous, especially for upscaling of the process: our hollow fiber module can handle larger sample volumes at a constant flux and therefore was chosen as the cross-flow system in the up-scaled process we describe later. However, on a smaller scale, the membrane cassettes may be preferable since the minimal volume needed for the cassette system is at $20 \mathrm{~mL}$ significantly smaller than the approx. $80 \mathrm{~mL}$ that are required for running the hollow fiber system. For better comparability and because no target protein was lost in the permeate, the small purification process was conducted with the $100 \mathrm{kDa}$ membrane cassette. The optimized parameters of $\Delta p_{\mathrm{TM}}=1$ bar and a pore size of $100 \mathrm{kDa}$ were also transferred to the diafiltration step after chromatography. The results are discussed in the summary of the purification process.

Size exclusion chromatography. After the concentration of mucus by cross-flow filtration, $20 \mathrm{~mL}(0.11 \mathrm{CV})$ of concentrated mucus $\left(0.42 \mathrm{mg} \mathrm{mL}^{-1}\right.$ Muc5AC) were injected onto a Sepharose 6 Fast Flow column. The obtained chromatogram showed two major peaks at a wavelength of $280 \mathrm{~nm}$ (Fig. 4). The first peak eluted after $52 \mathrm{~mL}(0.29 \mathrm{CV})$, whereas the major peak, containing proteins of smaller sizes appeared between 100 and 250 $\mathrm{mL}(0.57-1.4 \mathrm{CV})$. Fractions were analyzed for glycoproteins by qualitative PAS assay. Glycoproteins were mostly found in the first peak. Since the purity of mucin was of high importance to

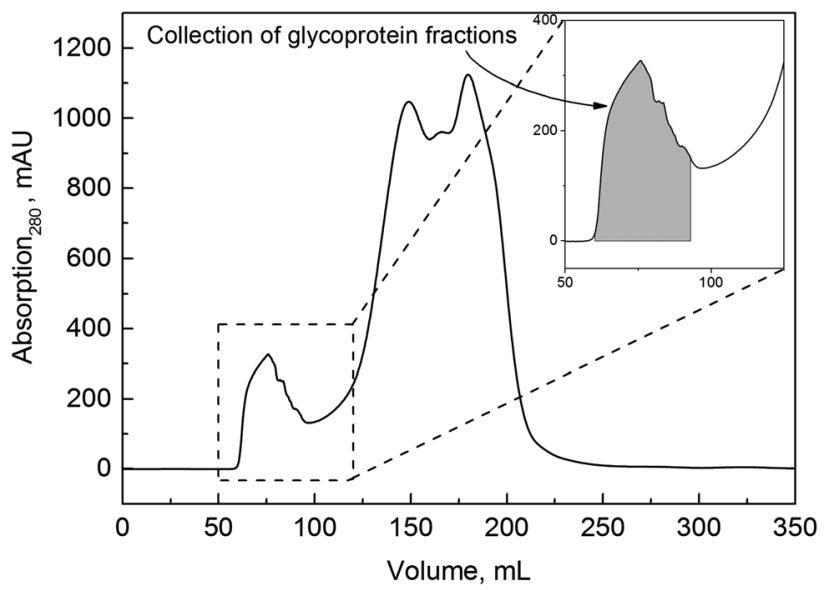

Fig. 4 Size exclusion chromatogram of concentrated mucus at 280 $\mathrm{nm}$. Flowrate: $30 \mathrm{~cm} \mathrm{~h}^{-1}$, column volume: $176 \mathrm{~mL}$, column diameter: $16 \mathrm{~mm}$, running buffer: $10 \mathrm{mM}$ phosphate buffer with $170 \mathrm{mM} \mathrm{NaCl}$, $\mathrm{pH}$ 7. The grey area indicates the fractions that were pooled after screening for glycoproteins with PAS assay.

obtain a gelation behavior at acidic $\mathrm{pH}$, the fractions that overlapped with the major peak containing contaminating proteins were omitted. The fractions (gray in Fig. 4) were finally pooled, analyzed for protein content and prepared for diafiltration. The Muc5AC concentration obtained was $0.38 \mathrm{mg}$ $\mathrm{mL}^{-1}$. Muc5AC was completely recovered (see also Table 1), whereas the recovery of general glycoprotein in the pooled fractions was only $83 \%$ (ESI Table S3†). This indicated that the SEC step was successful in further decreasing the content of non-mucin glycoproteins.

Diafiltration. For the diafiltration step, the optimized parameters of the concentration step $\left(\Delta p_{\mathrm{TM}}=1\right.$ bar and a pore size of $100 \mathrm{kDa}$ ) were used again. Since the process volume after SEC was small compared to the cassette volume, no further volume reduction of the target solution was possible. We performed diafiltration until the conductivity of the mucin solution was less than $100 \mu \mathrm{S} \mathrm{cm}^{-1}$ in the retentate. The reason for this choice was twofold: first, low ionic strength was required to successfully induce gelation of a $1 \%(\mathrm{w} / \mathrm{v})$ solution of purified mucin at $\mathrm{pH} 2 \cdot{ }^{15}$ Second, the diafiltrated mucin solution was, in a last step, lyophilized to receive a stable product that could be stored at room temperature. A low concentration of remaining ions in the lyophilized mucin allowed for reconstituting mucin solutions with arbitrary buffer conditions, i.e. both at high and low ionic strength.

Yield and productivity of the purification process. Maximum Muc5AC yields of $66 \%$ were achieved with the illustrated process referring to the concentration after centrifugation (see Fig. 1). The yields per purification step are summarized in Table 1. As already mentioned, purity was not determined quantitatively due to the possible underestimation of glycoproteins. Instead, SDS-PAGE (Fig. S3b †) showed that our purified mucin did not contain visible amounts of contaminating proteins with molecular weights smaller than $212 \mathrm{kDa}$. However, no statement can be made about the presence of other high molecular weight proteins such as similar glycoproteins. A 4.9 fold volume 
Table 1 Summary and yield of the overall Muc5AC purification process following the optimized protocol (i.e. mucus concentration with the 100 kDa membrane cassette system, Sepharose 6 Fast Flow size exclusion chromatography (CV = $176 \mathrm{~mL}), 100$ kDa diafiltration). Mucin yield, concentrations, process volumes and mass before and after each purification step, volume concentration factor VCF and concentration factor CF are given for each step. Determination of Muc5AC concentration was conducted with ELISA. Results shown represent the mean \pm s.d. of analytical triplicates

\begin{tabular}{|c|c|c|c|c|c|c|c|c|c|}
\hline Downstream process step & Yield, \% & $c_{\text {before }}, \mathrm{mg} \mathrm{mL}^{-1}$ & $c_{\text {after }}, \mathrm{mg} \mathrm{mL}^{-1}$ & $V_{\text {before, }}, \mathrm{L}$ & $V_{\text {after }}, \mathrm{L}$ & $m_{\text {before }}, \mathrm{mg}$ & $m_{\mathrm{after}}, \mathrm{mg}$ & VCF & $\mathrm{CF}$ \\
\hline Concentration & $73 \pm 7$ & $0.27 \pm 0.02$ & $0.42 \pm 0.01$ & 0.196 & 0.09 & $52.4 \pm 3.4$ & $38.1 \pm 0.2$ & $4.9^{b}$ & $3.5^{b}$ \\
\hline Chromatography & $113 \pm 6$ & $0.42 \pm 0.01$ & $0.38 \pm 0.03$ & 0.02 & 0.025 & $8.5 \pm 0.1$ & $9.5 \pm 0.6$ & - & - \\
\hline Lyophilization & - & & & 0.042 & & & $13.1^{a}$ & - & - \\
\hline Total & $66 \%$ & & & & & & $13.1^{a}$ & & \\
\hline
\end{tabular}

${ }^{a}$ Weighed after lyophilization; purified mucin after purification of $20 \mathrm{~mL}$ concentrated mucus. ${ }^{b}$ Before washing of membrane.

concentration with cross-flow filtration resulted in $40 \mathrm{~mL}$ retentate. The washing volume of $50 \mathrm{~mL}$ was also analyzed for Muc5AC content and pooled with the retentate, finally yielding a $90 \mathrm{~mL}$ retentate solution. A yield of $73 \%$ with the optimized concentration protocol was achieved. $20 \mathrm{~mL}$ (according to 0.11 $\mathrm{CV}$ ) of $90 \mathrm{~mL}$ retentate were loaded onto our gel filtration system. The purification using size exclusion chromatography resulted in a complete recovery of Muc5AC. In diafiltration, a yield of $80 \%$ was achieved. Due to different analysis methods there was a discrepancy in the calculated amount of Muc5AC after diafiltration $(7.6 \pm 0.3 \mathrm{mg})$ and the weight obtained after lyophilization $(13.1 \mathrm{mg})$. The increase by $5.5 \mathrm{mg}$ might be explained by the presence of other high molecular weight mucins such as Muc6 present in porcine stomach mucus ${ }^{\mathbf{4 6 , 4 7}}$ or residual DNA indicating that the purity of Muc5AC was around $60 \%$. For yield and productivity calculations and further experiments the lyophilized mucin was used. In total, $13.1 \mathrm{mg}$ mucin from $20 \mathrm{~mL}$ concentrated mucus before chromatography was purified. Assuming that no mucin was lost during the first process units until concentration the overall recovery was 1.0 $\mathrm{mg}$ mucin per $\mathrm{mL}$ crude mucus after stomach scraping. The productivity was $0.08 \mathrm{mg} \mathrm{mL}_{\text {crude mucus }}{ }^{-1} \mathrm{~h}^{-1}$ referring to the process time from the concentration of mucus, over SEC to diafiltration, not accounting lyophilization.

Scale-up of mucin purification. As mentioned earlier, the amount of scraped mucus and mucin concentration differed for each stomach. Although 20 to 60 stomachs were pooled before purification experiments, variances in initial mucin concentrations and scraping procedure were observed between the batches and might account for the 8.7 fold higher Muc5AC initial concentration of $2.34 \mathrm{mg} \mathrm{mL}^{-1}$.

To satisfy the demand of purified native mucin a scale-up to the 10 fold column volume of size exclusion chromatography was aimed for. Optimized parameters were transferred to the large scale and the scale-up was analytically analyzed in terms of concentration and concentration factors, yield and productivity. Its results are summarized in Table 2. A total Muc5AC yield of $33 \%$ was achieved. During concentration with the hollow fiber membrane the volume was reduced by a factor of 4 . Due to the high initial filtration volume, the washing volume has less impact compared to the small scale. The Muc5AC concentration was increased from 2.34 to $3.34 \mathrm{mg} \mathrm{mL}^{-1}$ resulting in a yield of $36 \%$. During SEC, again a total recovery of the target protein was obtained, while diluting the protein by a factor of 0.6 . During subsequent diafiltration with the $100 \mathrm{kDa}$ hollow fiber membrane salts were removed and the sample further concentrated by a factor of two in terms of volume and a factor of 1.7 with regard to Muc5AC. 85\% were yielded in the diafiltration step.

In total, $482 \mathrm{mg}$ mucin was purified from $180 \mathrm{~mL}$ concentrated mucus before SEC, accounting for $236 \mathrm{~mL}$ crude scraped mucus. The upscaled purification process was reproduced four times with a mean mucin amount of $382 \mathrm{mg}$, resulting in 1.63

Table 2 Summary and yield of the overall upscaled Muc5AC purification process following the optimized protocol (i.e. mucus concentration with the $100 \mathrm{kDa}$ hollow fiber system, Sepharose 6 Fast Flow size exclusion chromatography (CV=1650 mL), $100 \mathrm{kDa}$ hollow fiber diafiltration). Mucin yield, concentrations, process volumes and mass before and after each purification step, volume concentration factor VCF and concentration factor CF are given for each step. Determination of Muc5AC concentration was conducted with ELISA. Results shown represent the mean \pm s.d. of analytical triplicates

\begin{tabular}{|c|c|c|c|c|c|c|c|c|c|}
\hline $\begin{array}{l}\text { Downstream } \\
\text { process step }\end{array}$ & Yield, \% & $c_{\text {before }}, \mathrm{mg} \mathrm{mL}^{-1}$ & $c_{\mathrm{after}}, \mathrm{mg} \mathrm{mL}^{-1}$ & $V_{\text {before }}, \mathrm{L}$ & $V_{\text {after }}, \mathrm{L}$ & $m_{\text {before }}, \mathrm{mg}$ & $m_{\mathrm{after}}, \mathrm{mg}$ & VCF & $\mathrm{CF}$ \\
\hline Concentration & $36 \pm 32$ & $2.34 \pm 0.45$ & $3.34 \pm 0.86$ & 0.72 & 0.18 & $1685 \pm 324$ & $601 \pm 154$ & 4.0 & $3.2^{b}$ \\
\hline Diafiltration & $85 \pm 23$ & $2.18 \pm 0.22$ & $3.71 \pm 0.79$ & 0.3 & 0.15 & $655 \pm 66$ & $556 \pm 118$ & - & - \\
\hline Lyophilization & & 0.32 & & & & & $482^{a}$ & - & - \\
\hline Total & $33 \%$ & & & & & & $382^{c}$ & & \\
\hline
\end{tabular}

${ }^{a}$ Weighed after lyophilization; purified mucin after purification of $180 \mathrm{~mL}$ concentrated mucus. ${ }^{b}$ Before washing of membrane. ${ }^{c}$ Mean of $n=5$ purifications. 
mg of purified mucin per $\mathrm{mL}$ crude mucus. We were able to purify $65 \mathrm{mg}$ mucin per stomach with $40 \mathrm{~mL}$ mucus in one stomach (mean of 60 stomachs). During one purification process the content of up to six stomachs could be processed and their containing mucin purified. The productivity of the optimized upscaled process was $0.15 \mathrm{mg} \mathrm{mL}_{\text {crude mucus }}{ }^{-1} \mathrm{~h}^{-1}$.

The yields are in accordance to the yields achieved in the small scale and only differ in the concentration step $(36 \pm 32 \%$ compared to $73 \pm 7 \%$ in the small scale). The initial concentration of the target protein was $2.34 \mathrm{mg} \mathrm{mL}^{-1}$ and thus by factor 8.7 higher than the initial concentration of the small scale process $\left(0.27 \mathrm{mg} \mathrm{mL}^{-1}\right)$. These differences are most likely based on different batches, where mucin concentrations in the stomachs are not predictable. The tangential flow filtration of a highly concentrated solution, containing not only proteins but also rests of DNA, phospholipids and solutes causes a high concentration on the membrane surface, possibly triggering the buildup of a gel layer. ${ }^{\mathbf{4 8 , 4 9}}$ Even after the washing of the membrane and collection of the washing solution, the recovery of Muc5AC did not increase. In our previous studies performed with initially $0.2-0.3 \mathrm{mg} \mathrm{mL} \mathrm{m}^{-1}$ concentrated mucin solutions, no such loss of Muc5AC occurred (see also Fig. 2). The Muc5AC concentrations during the concentration and diafiltration step are nearly the same at 2.34 and $2.18 \mathrm{mg} \mathrm{mL}^{-1}$, respectively. However, in the concentration process many contaminating proteins were present while in the protein solution to be diafiltered an already purified solution was applied. Thus, fewer solutes accumulate on the membrane interface leading to a lower decrease in flux and higher recovery. ${ }^{50}$ Additionally, the standard deviation of $32 \%$ might be the result of varieties in ELISA signal. It has been stated that high concentrations of contaminating proteins or lipids might lead to cross reactivity with the target protein. ${ }^{51}$ This phenomenon is apparent with the high amount of contaminations from crude mucus like phospholipids and (glyco-) proteins and variances in biological material in general. Considering that the diafiltration step which was performed under the same conditions as the concentration step resulted in a yield of $85 \%$, underestimation of the Muc5AC concentration in the first filtration step is probable due to shielding of the antibody binding region. We observed that ELISA provided the most reliable results after the concentration step of mucus.

Although the time needed for filtration increased with the processed volume and the recovery of the concentration process was lower in the upscaled process, productivity was 2 fold compared to the small scale process due to the high load onto the size exclusion chromatography, being $0.15 \mathrm{mg}$ $\mathrm{mL}_{\text {crude mucus }}{ }^{-1} \mathrm{~h}^{-1}$.

\subsection{Quality control of purified mucin}

As described above, the optimized and upscaled process of PGM purification resulted in a considerable improvement of the overall mucin amount as well as in a 2 fold increase in productivity (i.e. purified mucin per $\mathrm{mL}$ crude mucus and time). The quality of the purified mucin obtained from the optimized process was assessed by testing if its unique properties were preserved. Only then would the purified mucin be suitable for academic or biomedical applications. We first analyzed the gelforming abilities of mucin at $\mathrm{pH} 2$ and then investigated the lubricity of mucin solutions. As a high density of sugar molecules is required for the superior lubricity of mucin solutions, ${ }^{\mathbf{4 1 8 , 1 9}}$ such friction force measurement can indirectly demonstrate the intactness of mucin glycosylation. Additionally, we probed the selective binding properties of mucins with co-localization experiments. ${ }^{2}$

Gelation of mucin solutions. For verifying the gel-forming abilities of purified mucin, rheological measurements were conducted. Fig. 5 depicts the frequency-dependent viscoelastic moduli $G^{\prime}$ and $G^{\prime \prime}$ as determined at a shear frequency of $1 \mathrm{~Hz}$ for $1 \%(\mathrm{w} / \mathrm{v})$ mucin solutions at $\mathrm{pH} 2$ and 6 . At acidic conditions, the purified mucin formed a clear gel with a shear stiffness in the range of $\sim 10^{1} \mathrm{~Pa}$ whereas at $\mathrm{pH} 6$ the viscous properties of the mucin solution dominated. This observation was the expected behavior for solutions of functional porcine gastric mucin $^{5,11,13-15}$ and showed that this important mucin property was preserved after process optimization and upscaling. In contrast, solutions reconstituted from commercial porcine gastric mucin (Sigma Aldrich type II and III) lacked the ability to form a gel at acidic pH. This suggested that the mucin was somehow damaged during the commercial purification process, potentially by breaking the molecule into subunits or affecting important chemical moieties of the glycoprotein due to harsh conditions during the purification procedure. ${ }^{16,24}$

Lubricity of mucin solutions. Solutions of porcine gastric mucins are excellent lubricants, especially in the boundary lubrication and mixed lubrication regime., ${ }^{\mathbf{4 1 8}, 19}$ Friction values measured in a steel/PDMS tribology pairing at low sliding speeds can be as low as $0.01 .^{19}$ These low friction values were suggested to originate from hydration lubrication: mucins adsorb very well on hydrophobic surfaces such as PDMS and form thin surface layers. ${ }^{4}$ In these mucin layers, the oligosaccharide side-chains on the mucin backbone bind water. During the application of shear forces, energy is dissipated by moving the water molecules in this mucin layer, and this leads

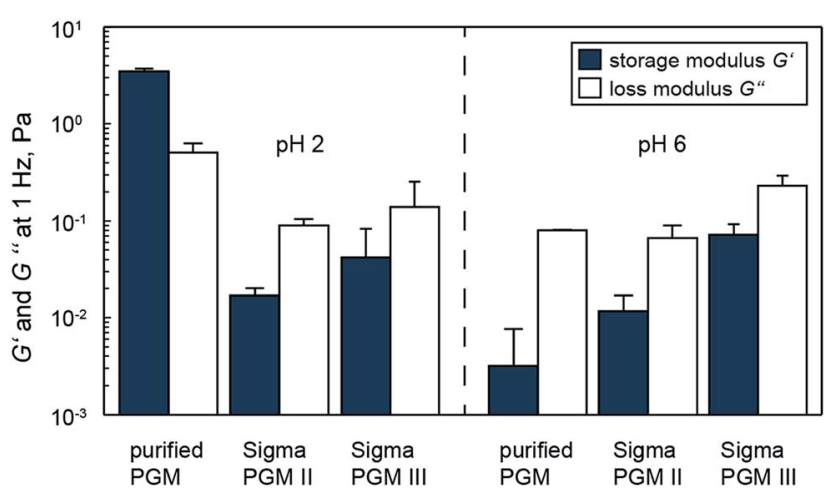

Fig. 5 Comparison of the storage modulus $G^{\prime}$ and loss modulus $G^{\prime \prime}$ of $1 \%(\mathrm{w} / \mathrm{v})$ mucin solution at acidic $(\mathrm{pH} 2)$ and nearly neutral $(\mathrm{pH} 6)$ conditions. Solutions of manually purified and commercial PGMs are compared. Only the manually purified mucin solutions show $\mathrm{pH}$ induced gelation. Error bars represent the \pm s.d. of analytical triplicates. 
to strongly reduced friction. In a tribological setup (see Experimental), we compared the friction between PDMS and steel when lubricated with $0.1 \%(\mathrm{w} / \mathrm{v})$ mucin solutions and compared this scenario to lubrication with $20 \mathrm{mM}$ HEPES buffer (pH 7). As displayed in Fig. 6, mucin solutions obtained from the optimized and upscaled purification process do indeed reach very low friction values around 0.01 and showed a good lubricity. In contrast, the commercial PGMs type II and III from Sigma Aldrich were poor lubricants, especially in the boundary lubrication regime, where their lubricity was virtually indistinguishable from buffer without mucin. We speculated that, for the commercial mucins, either the formation of a mucin surface layer is disturbed or mucin hydration is low. ${ }^{\mathbf{1 9}}$

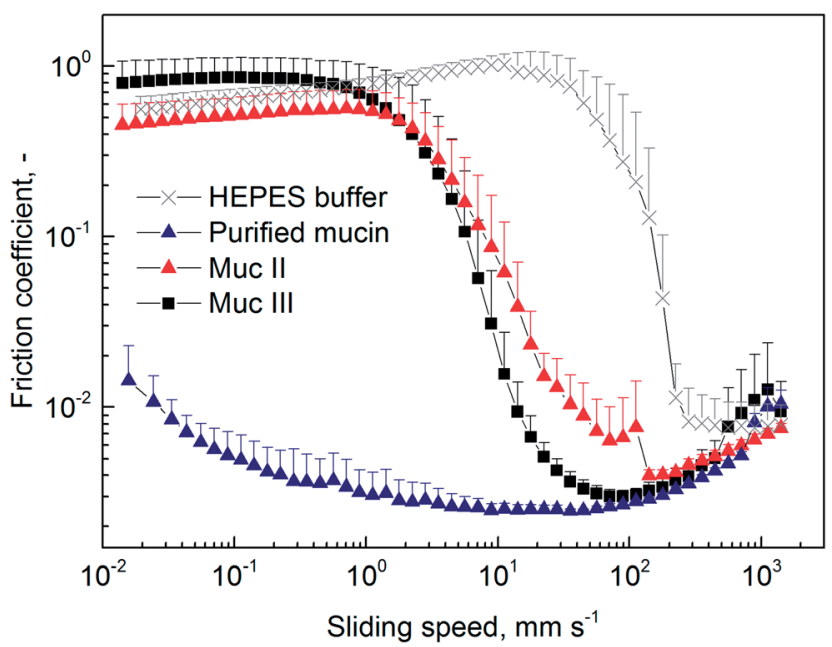

Fig. 6 Lubrication of a PDMS/steel setup with 20 mM HEPES buffer $(\mathrm{pH})$ or $0.1 \%$ mucin solutions (self-purified PGM or commercial PGM type II and III, dissolved in 20 mM HEPES, pH 7). The friction coefficient was determined over a broad range of sliding speeds. Error bars represent the s.d. obtained from analytical triplicates.
Selective permeability of mucin gels. In the body of mammalians, mucin gels constitute a barrier towards pathogens and bacteria., ${ }^{2,3}$ Previous studies showed that PGM convey selective permeability to mucin gels: depending on their surface charge, particles and molecules show different mobility in mucus and reconstituted mucin gels. Mucin glycoproteins carry several negative charges, especially through sialic acid or sulfate groups. ${ }^{11}$ As a consequence, mucins have been described to bind cationic molecules with much higher efficiency than anionic molecules. ${ }^{20,52}$ Therefore, we compared the behavior of two different fluorescently labelled dextran variants in mucin gels: anionic carboxymethyl dextran (CM-dextran) and cationic diethylaminoethyl dextrans (DEAE-dextran) in mucin gels at $\mathrm{pH}$ 2. Fig. 7 depicts the outcome of a co-localization experiment. Whereas anionic dextrans homogeneously distributed in the mucin gel, the cationic dextrans colocalized with the mucins. This verified that gels reconstituted from purified mucin exhibit selective permeability. Since the commercial PGMs do not form gels at acidic $\mathrm{pH}$, the selective binding properties of these mucins could not be assessed here.

\section{Conclusions}

Mucins from porcine stomachs intended for lubrication studies or virus-mucin interaction studies ${ }^{\mathbf{1 9 , 5 3}}$ have recently gained much attention. However, most commercially available PGMs lack crucial properties, in particular the ability to form gels at acidic $\mathrm{pH}$ and possessing sufficient lubricity. We have described a successful purification process for native mucin from pig stomachs that satisfies the demands of functional PGM for biomedical applications. Furthermore, we evaluated and improved important aspects of protein purification including buffer composition, volume reduction, efficiency, yield and functionality of the purified mucin. We were able to purify 65

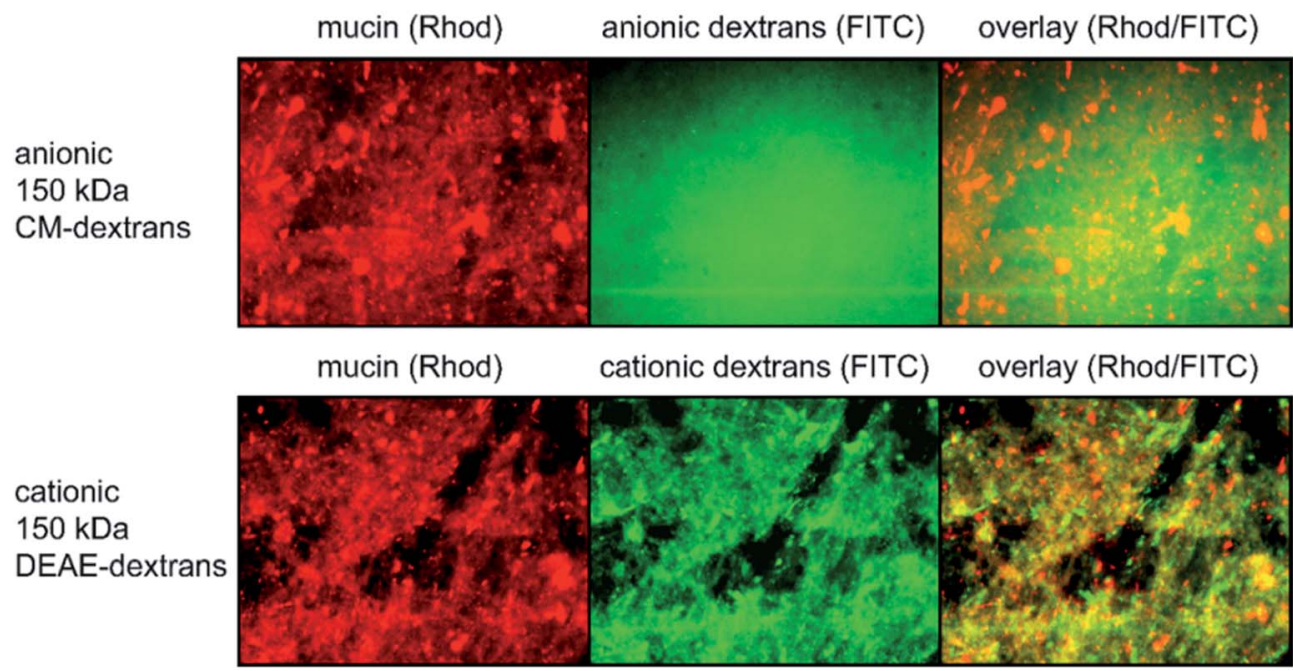

Fig. 7 Selective permeability of mucin gels reconstituted at $\mathrm{pH}$ 2: fluorescence microscopy images of rhodamine labeled mucin mixed with FITC-labeled 150 kDa charged dextran molecules. The rhodamine channel depicts the spatial distribution of mucin, the FITC channel the distribution of dextran molecules. The two channels are merged into one picture, displayed in the overlay image and show the co-localization of cationic dextrans and mucin. 
mg mucin per pig stomach at a productivity of $0.15 \mathrm{mg}$ mucin per mL crude mucus and hour. The process was successfully upscaled with the purified mucin retaining the desired key properties of gel formation at acidic $\mathrm{pH}$, lubricity and preservation of binding interactions with charged molecules.

The purification method discussed here can be applied to a wide range of diverse high molecular weight glycoproteins including mucins obtained from various sources such as those from human saliva. Because synthetic mucins with the identical properties of PGM are not available yet, efficient purification of endogenous mucins remains the only viable strategy for largescale production of these glycoproteins. In future studies, we intend to introduce alternative capture steps such as liquidliquid extraction to further optimize productivity to meet the increasing demand for these glycoproteins in research and biomedical applications.

\section{Abbreviations}

$\begin{array}{ll}\text { BSA } & \text { Bovine serum albumin } \\ \text { CF } & \text { Concentration factor } \\ \text { CV } & \text { Column volume } \\ \text { FITC } & \text { Fluorescein isothiocyanate } \\ \text { GI } & \text { Gastrointestinal tract } \\ \text { Muc5AC } & \text { Mucin 5AC } \\ \text { MWCO } & \text { Molecular weight cut off } \\ \text { PDMS } & \text { Polydimethylsiloxane } \\ \text { PGM } & \text { Porcine gastric mucin } \\ \text { S.d. } & \text { Standard deviation } \\ \text { SEC } & \text { Size exclusion chromatography } \\ \text { VCF } & \text { Volume concentration factor }\end{array}$

\section{Acknowledgements}

We thank Franziska Hirschmann and Eda Isik for conducting pilot experiments and Sabine Günzkofer for technical assistance. The project has been funded by the Dean's Innovation Fond of the TUM Department of Mechanical Engineering of the Technical University of Munich. OL and BTK gratefully acknowledge the financial support of the Deutsche Forschungsgemeinschaft (DFG) through grant LI 1902/3-1.

\section{Notes and references}

1 A. Allen, The structure and function of gastrointestinal mucus, in Basic Mechanisms of Gastrointestinal Mucosal Cell Injury and Protection, Baltimore, 1981.

2 O. Lieleg, C. Lieleg, J. Bloom, C. B. Buck and K. Ribbeck, Biomacromolecules, 2012, 13, 1724-1732.

3 M. A. McGuckin, S. K. Lindén, P. Sutton and T. H. Florin, Nat. Rev. Microbiol., 2011, 9, 265-278.

4 S. Lee, M. Müller, K. Rezwan and N. D. Spencer, Langmuir, 2005, 21, 8344-8353.

5 X. Cao, R. Bansil, K. R. Bhaskar, B. S. Turner, J. T. LaMont, N. Niu and N. H. Afdhal, Biophys. J., 1999, 76, 12501258.

6 L. A. Sellers, A. Allen, E. R. Morris and S. B. Ross-Murphy, Carbohydr. Res., 1988, 178, 93-110.
7 R. Mejías-Luque, L. Cobler and C. de Bolós, Atlas of Genetics and Cytogenetics in Oncology and Haematology, 2011, vol. 14, pp. 566-569.

8 A. J. Libao-Mercado and C. F. M. de Lange, Livest. Sci., 2007, 109, 141-144.

9 B. Jan-Willem Van Klinken, A. W. C. Einerhand, H. A. Büller and J. Dekker, Anal. Biochem., 1998, 265, 103-116.

10 G. J. Strous and J. Dekker, Crit. Rev. Biochem. Mol. Biol., 1992, 27(1/2), 57-92.

11 R. Bansil and B. S. Turner, Curr. Opin. Colloid Interface Sci., 2006, 11, 164-170.

12 K. Jumel, I. Fiebrig and S. E. Harding, Int. J. Biol. Macromol., 1996, 18, 133-139.

13 A. Maleki, G. Lafitte, A. L. Kjoniksen, K. Thuresson and B. Nystrom, Carbohydr. Res., 2008, 343, 328-340.

14 K. R. Bhaskar, D. H. Gong, R. Bansil, S. Pajevic, J. A. Hamilton, B. S. Turner and J. T. LaMont, Am. J. Physiol., 1991, 261, G827-G832.

15 J. P. Celli, B. S. Turner, N. H. Afdhal, R. H. Ewoldt, G. H. McKinley, R. Bansil and S. Erramilli, Biomacromolecules, 2007, 8, 1580-1586.

16 J. Kočevar-Nared, J. Kristl and J. Šmid-Korbar, Biomaterials, 1997, 18, 677-681.

17 I. C. Hahn Berg, L. Lindh and T. Arnebrant, Biofouling, 2004, 20, 65-70.

18 J. M. Coles, D. P. Chang and S. Zauscher, Curr. Opin. Colloid Interface Sci., 2010, 15, 406-416.

19 T. Crouzier, K. Boettcher, A. R. Geonnotti, N. L. Kavanaugh, J. B. Hirsch, K. Ribbeck and O. Lieleg, Adv. Mater. Interfaces, 2015, 2, 1500308.

20 L. D. Li, T. Crouzier, A. Sarkar, L. Dunphy, J. Han and K. Ribbeck, Biophys. J., 2013, 105, 1357-1365.

21 A. A. Feiler, A. Sahlholm, T. Sandberg and K. D. Caldwell, J. Colloid Interface Sci., 2007, 315, 475-481.

22 O. Lieleg, I. Vladescu and K. Ribbeck, Biophys. J., 2010, 98, 1782-1789.

23 N. V. Efremova, Y. Huang, N. A. Peppas and D. E. Leckband, Langmuir, 2002, 18, 836-845.

24 O. Svensson and T. Arnebrant, Curr. Opin. Colloid Interface Sci., 2010, 15, 395-405.

25 M. Faure, D. Moënnoz, F. Montigon, L. B. Fay, D. Breuillé, P. A. Finot, O. Ballèvre and J. Boza, Anal. Biochem., 2002, 307, 244-251.

26 M. Mantle and A. Allen, Biochem. J., 1981, 195, 267-275.

27 T. Marshall and A. Allen, Biochem. J., 1978, 173, 569-578.

28 R. Gupta, N. Jentoft, A. M. Jamieson and J. Blackwell, Biopolymers, 1990, 29, 347-355.

29 J. Dekker, W. Van Beurden-Lamers, A. Oprins and G. J. Strous, Biochem. J., 1989, 260, 717-723.

30 T. Melin and R. Rautenbach, Membranverfahren Grundlagen der Modul- und Anlagenauslegung, Springer Verlag, 2007.

31 B. Espinasse, P. Bacchin and P. Aimar, Desalination, 2002, 146, 91-96.

32 S. Ripperger and T. Grein, Chem. Ing. Tech., 2007, 79, 17651776. 
33 M. Kilcoyne, J. Q. Gerlach, M. P. Farrell, V. P. Bhavanandan and L. Joshi, Anal. Biochem., 2011, 416, 18-26.

34 K. Boettcher, S. Grumbein, U. Winkler, J. Nachtsheim and O. Lieleg, Rev. Sci. Instrum., 2014, 85, 093903.

35 I. Carlstedt, H. Lindgren, J. K. Sheehan, U. Ulmsten and L. Wingerup, Biochem. J., 1983, 211, 13-22.

36 J. P. Pearson, A. Allen and S. Parry, Biochem. J., 1981, 197, 155-162.

37 Z. Kučerová, H. Muselová, E. Miarková and M. Tichá, Prague Med. Rep., 2010, 111, 200-206.

38 M. Scawen and A. Allen, Biochem. J., 1977, 163, 363-368.

39 N. Jentoft, Trends Biochem. Sci., 1990, 15, 291-294.

40 A. Allen and A. Garner, Gut, 1980, 21, 249-262.

41 D. W. Piper and B. H. Fenton, Gut, 1965, 6, 506-508.

42 A. Saxena, B. P. Tripathi, M. Kumar and V. K. Shahi, Adv. Colloid Interface Sci., 2009, 145, 1-22.

43 R. Bansil, E. Stanley and J. T. Lamont, Annu. Rev. Physiol., 1995, 57, 635-657.

44 M. Malmsten, E. Blomberg, P. Claesson, I. Carlstedt and I. Ljusegren, J. Colloid Interface Sci., 1992, 151, 579-590.
45 L. Shi and K. D. Caldwell, J. Colloid Interface Sci., 2000, 224, 372-381.

46 H. Nordman, J. R. Davis, A. Herrmann, N. G. Karlsson, G. C. Hansson and I. Carlstedt, Biochem. J., 1997, 326, 903910.

47 S. K. Linden, P. Sutton, N. G. Karlsson, V. Korolik and M. A. McGuckin, Mucosal Immunol., 2008, 1, 183-197.

48 L. G. Peeva, E. Gibbins, S. S. Luthra, L. S. White, R. P. Stateva and A. G. Livingston, J. Membr. Sci., 2004, 236, 121-136.

49 L. Song and M. Eiimelech, J. Chem. Soc., Faraday Trans., 1995, 91, 3389-3398.

50 G. B. van den Berg and C. A. Smolders, Desalination, 1990, 77, 101-133.

51 J. Schiettecatte, E. Anckaert, J. Smitz, Adv. Immunoassay Technol., ed. N. H. Chiu, InTech, Croatia, 2012, ch. 3, pp. 45-62.

52 C. Nowald, A. Penk, H.-Y. Chiu, T. Bein, D. Huster and O. Lieleg, Macromol. Biosci., 2016, 16, 567-579.

53 B. A. Dancho, H. Chen and D. H. Kingsley, Int. J. Food Microbiol., 2012, 155, 222-226. 